\title{
Neurophysiological investigation in optic nerve disease: combined assessment of the visual evoked response and electroretinogram
}

\author{
HISAKO IKEDA, K. E. TREMAIN, AND M. D. SANDERS \\ From the Vision Research Unit, the Rayne Institute, and the Eye Department, St. Thomas's Hospital, London
}

SUMMARY The electroretinogram (ERG) and the pattern visual evoked responses (VER) obtained from patients with suspected primary optic nerve lesions have been analysed. Patients with hereditary optic atrophy or optic nerve lesions with retinal disease or with systemic disorders were excluded from the analysis.

According to the results of the ERG functions and VER, 83 patients with suspected primary optic nerve lesion could be classified into 3 categories. (1) Normal ERG functions, VER with normal amplitude but with delayed peak or with significant interocular difference in the peak time, suggesting a lesion in the myelin sheath of the optic nerve. (2) Subnormal ERG functions, VER with subnormal amplitude and with delayed peak or with significant interocular difference in the peak time, suggesting axonal as well as myelin involvement, leading to orthograde and retrograde transneuronal 'degeneration'. (3) Subnormal ERG functions, VER with subnormal amplitude but without a delayed peak and without interocular difference in the peak time, suggesting a generalised cellular and axonal involvement.

Patients classified into the above 3 groups were then correlated with clinical findings. The first group of patients (category 1), showed either a number of neurological symptoms to suggest multiple sclerosis without any visual deficit or a sudden transient loss of vision accompanied by pain in the affected eye. They were finally diagnosed as multiple sclerosis with optic neuritis. The second group of patients (category 2), had similar case histories to those of category 1 but showed a more severe, permanent loss of vision, commonly with temporal pallor and pupillary defects. The final diagnoses of these patients were either multiple sclerosis or compressive or ischaemic optic neuropathies. The third group of patients all showed bilateral, gradual, painless loss of vision but were subdivided into 2 distinct clinical diagnostic categories: (a) toxic amblyopia (category 3 ), and $(b)$ bilateral optic atrophy of unknown cause (category 4).

Neurophysiological studies of the visual system of the cat and monkey using microelectrodes have made great advances in revealing the elegant but intricate organisation of the cells, axons, and synapses of the primary afferent visual system. However, when one is faced with the problem of understanding the nature and degree of abnormality of the visual system in patients with loss of visual function, the only electrophysiological method available to investigate the functional state of the primary afferent visual system is the evoked response technique. The electroretinogram (ERG) and the visual evoked response (VER) are the two major

Address for reprints: M. Sanders, FRCS, The Eye Department, St. Thomas's Hospital, London SE1 7EH techniques which contribute to the neurophysiological assessment of the visual system in clinical medicine.

The ERG measures the graded electrical response of the cells (mainly the photoreceptors and the bipolar cells) in the outer layers of the retina by a corneal electrode. By manipulating and controlling the stimulating conditions, the ERG can reveal the state of the scotopic and photopic functions of the retina. The normal ERG requires (1) normal pigment epithelium, (2) normal rods and cones, (3) normal rod and cone pigments, (4) normal outer synaptic layer with normal synaptic transmission, (5) normal inner nuclear layer, and (6) normal retinal and choroidal circulation (see Ikeda, 1976).

The VER is the averaged electrical response of 
the visual cortex evoked by repetitive visual stimulation and is used as an indicator of retinocortical conduction and the degree of synchronous excitation at the visual cortex. Owing to the cortical magnification factor the occipital lobe receives a disproportionately large projection from the foveal retina. Thus the VER represents mainly the reception of the message arising from the central retinal zone.

Although precise localisation of a lesion in the visual pathway is practically impossible in the clinical situation by the use of these 2 techniques, we have attempted to see whether or not a more detailed analysis of the ERG and the VER may assist in the diagnosis of different optic nerve diseases. Such an attempt is not new, since the ERG has been used for the assessment of retinal abnormality for many years (Karpe, 1945). Dawson (1954) introduced an averaging technique for detecting small signals in a noisy electroencephalogram (EEG), and since then VER studies in man have evolved as a diagnostic procedure in assessing patients with non-retinal disorders (c.f. Feinsod et al., 1971; Regan, 1972; Arden, 1973; Halliday, 1975; McDonald and Halliday, 1977).

In the present work both the ERG and VER have been recorded in the same patient and used for routine clinical testing on patients whose diagnosis was uncertain. The patients with whom we are concerned in this paper are those who came to the electrodiagnostic unit with a provisional diagnosis suggesting optic nerve involvement, such as optic neuritis, multiple sclerosis, ischaemic optic neuropathies, compressive lesion, optic atrophy, or toxic amblyopia. We have excluded patients with obvious primary retinal lesions.

The question we asked was whether we can differentiate this confusing assortment of patients into categories defined on the basis of different types of lesion. An abnormality of the optic nerve can be caused by the following types of lesion: (1) simple demyelination, (2) severe demyelination plus degenerative changes in the axons, and (3) more generalised neuronal degeneration which might be reversible or irreversible. Axonal lesions of the optic nerve would be expected to produce orthograde and retrograde transynaptic degeneration, and the latter should be detectable from the ERG. The VER and ERG have therefore been used as a combined assessment of optic nerve function, in order to localise lesions and provide the clinician with accurate diagnostic information.

\section{Materials}

Table 1 lists the number of subjects studied in the series. The 10 control volunteer subjects were all either staff or students of St. Thomas's Hospital. Among 142 patients sent to the electrodiagnostic unit $25(17.6 \%)$ showed a normal VER in every respect, and these are included in the control group in making up the total control subjects to 35 .

The remaining 117 patients $(82.4 \%)$ were sent to the unit with visual impairment attributed to optic nerve disease. Analysis of the case notes of these patients revealed that 11 had additional ocular findings, such as macular changes, choroidal sclerosis, retinal haemorrhages, uveitis, or retinal pigmentary changes, and 4 had a systemic disease. Thus 15 patients $(10.6 \%)$ were excluded from the present study. In addition we excluded 19 patients $(13.4 \%)$ whose diagnosis was Leber's optic atrophy, dominant optic atrophy, or familial optic atrophy in which a hereditary origin had been suggested, since we felt these required a separate investigation. A total of 83 patients $(58.5 \%)$ remained and provided the basis for this investigation.

None of the patients was sent to the electrodiagnostic unit for the purpose of this study. Thus the sample represents a fairly common cross-section found in a large London general teaching hospital. All material was collected over a 7-month period (from December 1976 to June 1977).

\section{Methods}

The technique used to record averaged VER to pattern reversal stimuli was similar to that described by Halliday et al. (1972, 1973a). The response was routinely recorded between the mid-occipital $(5 \mathrm{~cm}$ above the inion) and mid-frontal reference electrodes. The contact resistances of the electrode were maintained at $1.5 \mathrm{~K} \Omega$ or less in every patient. The patient sat facing a translucent screen subtending a visual angle of $30^{\circ}$. The black-and-white checkerboard pattern (44' of arc squares) back projected upon the screen was reversed in phase at $2 \mathrm{~Hz}$ by

Table 1 Number of controls and patients with optic nerve lesions studied

\begin{tabular}{lll}
\hline Subjects & Numbers & Included or excluded \\
\hline $\begin{array}{l}\text { Normal volunteers (aged 18-35) } \\
\begin{array}{l}\text { Patients with normal VER } \\
\text { (aged 12-56) }\end{array}\end{array}$ & 10 & Included as control \\
$\begin{array}{l}\text { Patients with additional complaints } \\
\text { (provisionally diagnosed as optic } \\
\text { atrophy) }\end{array}$ & 15 & Included as control \\
$\begin{array}{l}\text { Patients with hereditary optic } \\
\text { atrophy }\end{array}$ & 19 & Excluded \\
$\begin{array}{l}\text { Patients with suspected optic nerve } \\
\text { lesion (aged 34-61) }\end{array}$ & 83 & $\begin{array}{c}\text { Excluded } \\
\text { Included as patients } \\
\text { for this study }\end{array}$ \\
\hline
\end{tabular}


a mirror mounted on a pen motor driven by a square wave $2 \mathrm{~Hz}$ function generator. There was a delay of $6 \mathrm{~ms}$ between the trigger pulse and the displacement of the pattern as determined by a photo cell with a rise time of $1.5 \mu \mathrm{s}$. The luminance level of the bright phase of the checkboard was $215 \mathrm{~cd} / \mathrm{m}^{2}$ and that of the black phase $20 \mathrm{~cd} / \mathrm{m}^{2}$.

A small fixation point was provided at the centre of the screen and the patient was encouraged to maintain steady fixation of the target during averaging. This precaution was essential in obtaining the VERs on which reliable measurements could be made. The fixation target was changed in size according to the visual acuity of the patient.

The potential recorded was amplified and averaged using a Medelec DA V6 averager (band width of amplifier, $0.16 \mathrm{~Hz}$ to $0.8 \mathrm{kHz}$ ). In every patient refractive errors were corrected by lenses and each eye was tested separately. Routinely 100 to 200 responses were averaged, but more than 500 for small VERs. The peak latency and amplitude of the major positive wave were measured as described by Halliday et al. (1976).

\section{ERG}

The recordings of the ERG were made between an active electrode on the cornea and a reference electrode on the forehead. The corneal electrode was a fine silver wire ring embedded in a contact lens. The contact lens had a suction device fitted to ensure that the relative position between the electrode and the cornea did not change; its outer portion where the silver wire ring electrode was embedded was made opaque, so that stimuli entered only from the central transparent part of the lens, which acted as an artificial pupil of $6 \mathrm{~mm}$ diameter. The pupils were fully dilated by Mydrilate (cyclopentolate eye drops $B P C 1 \%$, and this together with the artificial pupil on the contact lens standardised the amount of light entering the eye. The cornea was anaesthetised with a topical anaesthetic (amethocaine eye drops $B P C 1 \%$ ) and the lens electrode made electrical contact with the cornea through a conductive fluid, isotonic $(0.9 \%)$ saline. The reference electrode was a silver-chloride impregnated disc fastened to the skin. The patient lay on a bed with a firm head rest.

The potential difference between the 2 electrodes was suitably amplified and the response displayed on a pen recorder or on an oscilloscope. The stimulating flash was a xenon-filled gas discharge tube mounted in a 4-cm diameter reflector with a diffusing screen. The flash tube screen was placed $6 \mathrm{~cm}$ from the eye of the patient. A light-tight filter carrier was placed just in front of the flash tube screen, allowing the intensity of the flash to be controlled by cali- brated neutral density filters, and the wavelength by a scotopic blue filter (Kodak 47B) or a photopic red filter (Kodak 29).

The flash was extremely brief (time to peak, $4 \mu \mathrm{s}$ with exponential decay to $1 / \mathrm{e}$ of the peak intensity in $25 \mathrm{~ms}$ ), and the luminance of the screen without any neutral density filter interposition was $10^{7} \mathrm{~cd} / \mathrm{m}^{2}$ during the flash.

In each patient, when the base line had stabilised, 2 optimal intensity flashes were applied to evoke light adapted ERGs, a 2-log units filter was interposed between the flash screen and the eye, and the room was completely darkened.

The eye was stimulated by 2 flashes separated by approximately 10 seconds at every 2 minutes for 12 minutes of the dark adaptation period, and an increase in the b-wave amplitude was observed. After 12 minutes in the dark the flash intensity was progressively reduced in steps of $0 \cdot 5-\log$ units down to threshold, that is, the lowest intensity of flash for which a just discernible scotopic b-wave could be obtained. Then the intensity of the flash was progressively increased again in $0 \cdot 5-\log$ unit steps to the optimal flash intensity, thus providing measurements of the b-wave amplitude as a function of relative $\log$ intensity of stimulating flash. Thereafter flicker ERG was obtained using a photopic red flash (with Kodak 29) progressively increasing the flashing rate from 5 to $30 \mathrm{~Hz}$ in $5-\mathrm{Hz}$ steps. The amplitude of the wavelets of the recorded flicker ERG were then measured.

\section{Results}

\section{Definition of normal VER}

The measurements made of the major positive peak of the pattern-evoked VERs obtained from 70 normal eyes of 35 control subjects are shown on the extreme left of Figs. 1, 2, and 3. Distribution of amplitudes of the major positive peak is shown in Fig. 1 and that of the peak latencies in Fig. 2. In Fig. 3 interocular difference in the peak latencies was plotted.

On the basis of the control data we can define the normal VER to be that which satisfied the following 3 criteria: (1) The amplitude of the major positive peak is over $7.5 \mu \mathrm{V}$; (2) latency to the peak of the major positive peak, less than $115 \mathrm{~ms}$; (3) interocular difference in the peak latency less than $4 \mathrm{~ms}$.

\section{Classification of VERs in patients in different categories}

Having defined the normal VER we could classify all VERs recorded from the patients which did not satisfy the 3 criteria for the normal VER into 3 categories. 

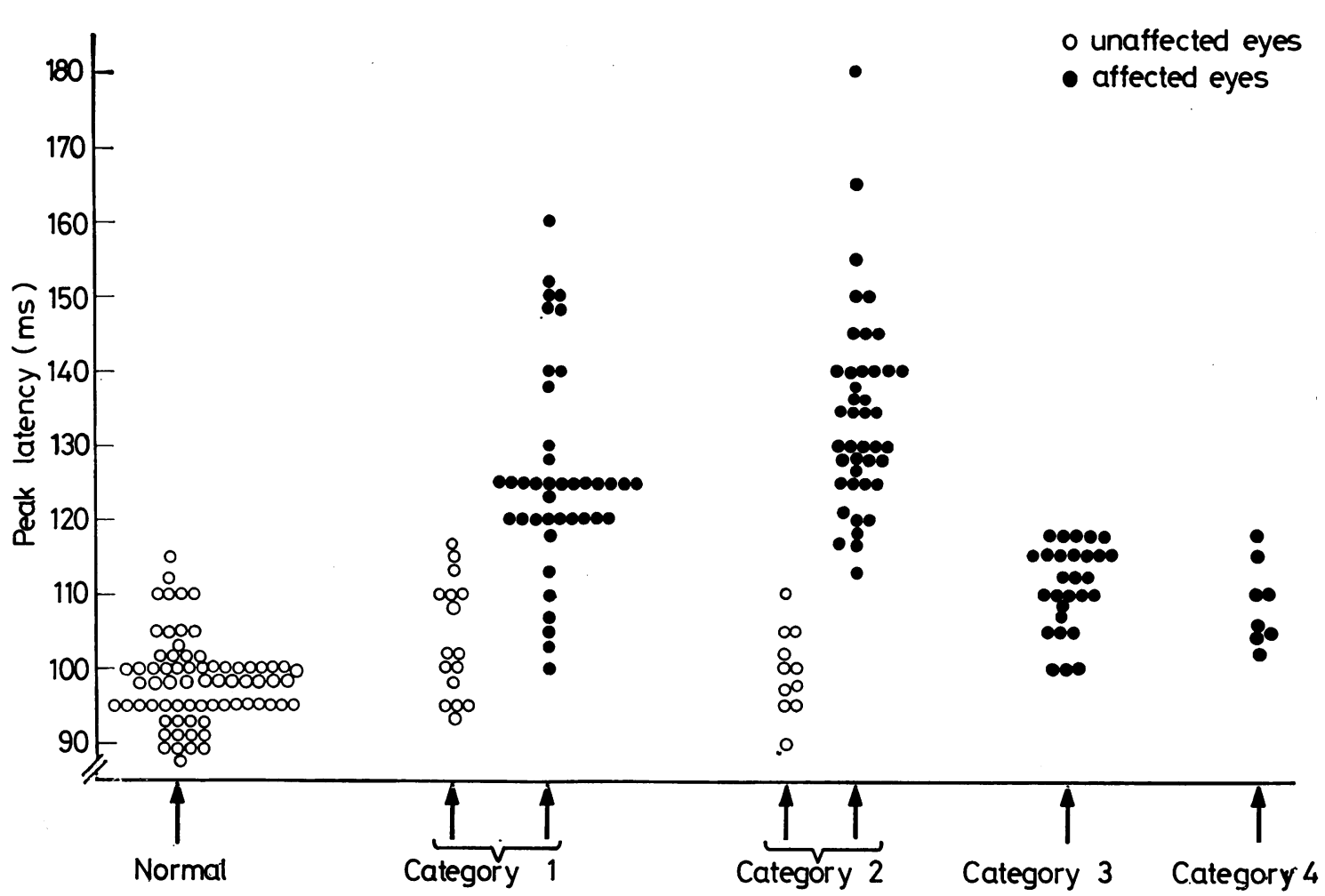

Fig. 1 Amplitude of the major positive peak of the pattern VER recorded from the normal group and patients in categories 1, 2, 3, and 4. Each point represents the VER recorded by stimulating through 1 eye only

Category (1) patients satisfied only the first criterion, i.e., the amplitude of the major positive wave is over $7 \cdot 5 \mu \mathrm{V}$ (the second column in Fig. 1), but both eyes showed a peak latency longer than $115 \mathrm{~ms}$ (second column in Fig. 2) and/or the interocular difference of the peak latency is greater than $5 \mathrm{~ms}$ (second column in Fig. 3). We have included 6 cases in which, although the affected eye's VER showed normal amplitude and a latency below $110 \mathrm{~ms}$, nevertheless the latency was consistently longer for the affected eye's VER by greater than $5 \mathrm{~ms}$.

Category (2) patients showed (1) subnormal amplitude (below $7.5 \mu \mathrm{V}$-third column in Fig. 1), and (2) peak latencies longer than $115 \mathrm{~ms}$ except for 1 patient (the third column in Fig. 2), in whom the peak latency of his normal eye was $102 \mathrm{~ms}$ whereas that of the affected eye was 113 ms. Thus the interocular latency difference was $11 \mathrm{~ms}$, not satisfying criterion 3 (third column in Fig. 3). Again even if the interocular difference was below $4 \mathrm{~ms}$, if the patient showed subnormal and delayed VER for both eyes they were put in this category.

Category (3) patients showed bilaterally subnormal VERs (see fourth column in Fig. 1) and no interocular latency difference (see fourth column in Fig. 3). The peak latencies of the small VERs from these patients were not markedly different from those of normal subjects. Although the mean peak latency was significantly delayed compared with the normal controls $(P<0.001)$, most values were within the normal range (see fourth column in Fig. 2).

After classification of all the VERs into the above 3 categories a fourth category became necessary because clinical criteria provided a clearly demarcated subdivision. The patients in category 3 , with similar neurophysiological findings, could be clinically subdivided with those with a toxic amblyopia and those with bilateral optic atrophy of unknown aetiology. We included all patients with a history of smoking and drinking and supportive clinical and biochemical evidence in category 3 , but those with only optic atrophy in category 4 (see fifth column in Figs. 1, 2, and 3).

The mean, standard deviation, and range of the peak amplitude and latency of the pattern VER in each group on which the statistics have been carried out are shown in Table 2. Table 3 shows the data for interocular latency difference. 


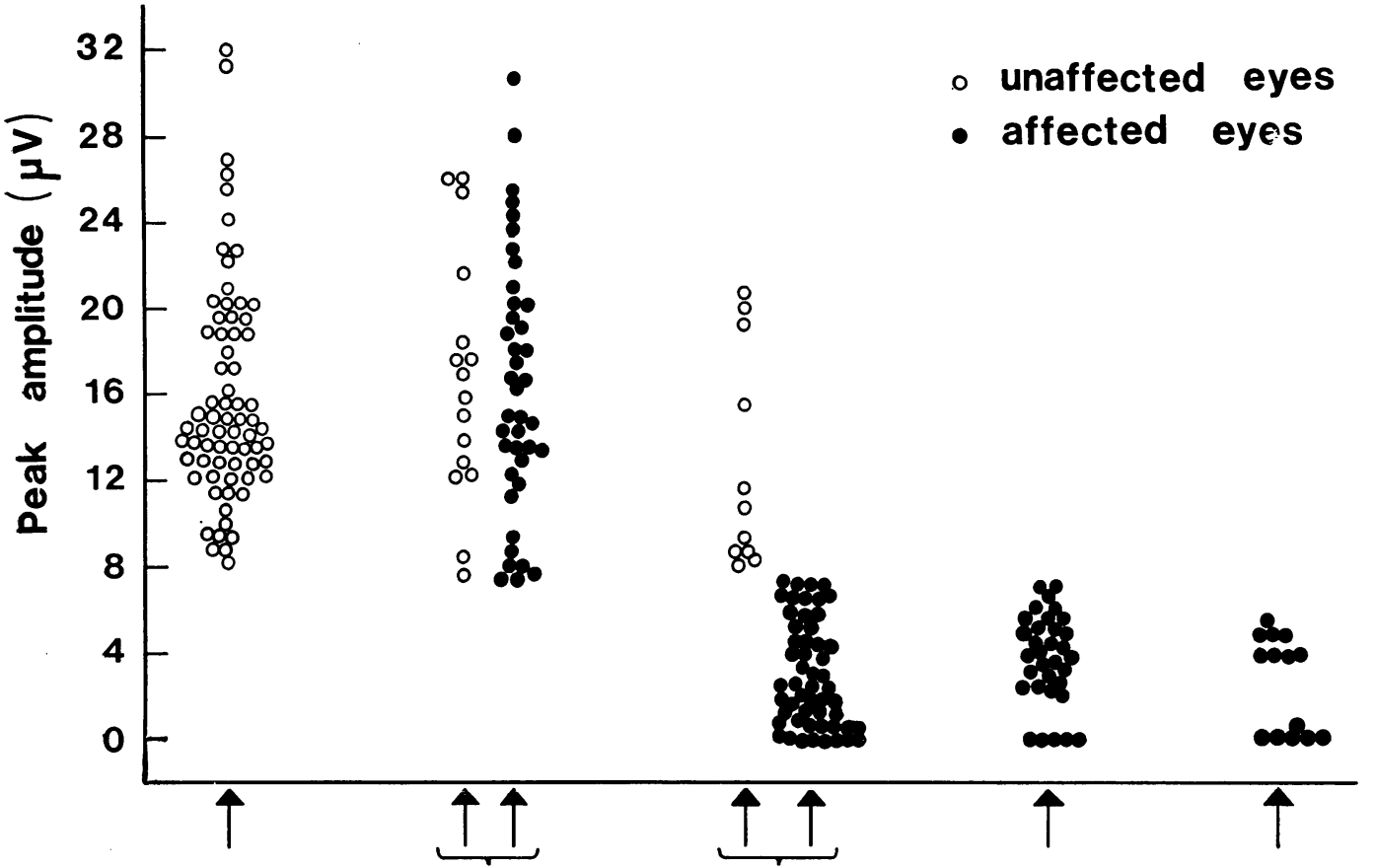

Normal Category 1 Category 2 Category 3 Category 4

Fig. 2 Latency of the major positive peak of the pattern VER recorded from the normal group and patients in categories 1, 2, 3, and 4. Each point represents the VER recorded by stimulating through 1 eye only

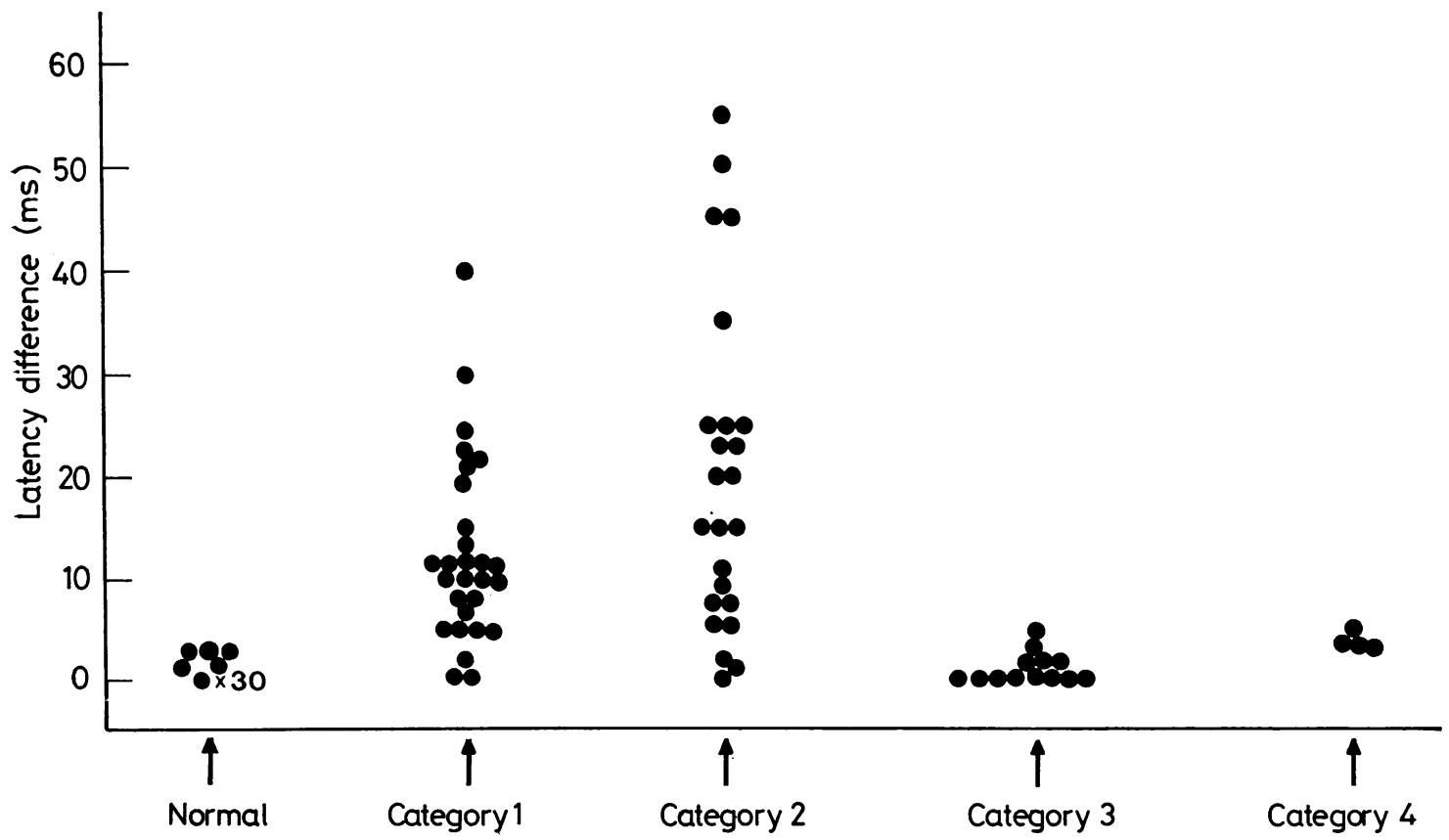

Fig. 3 Interocular differences in latency of the major positive peak of the pattern VER recorded from the normal group and patients in categories 1,2,3, and 4. Thirty people in the normal group had equal latencies in both eyes 
Table 2 Pattern VER data

\begin{tabular}{|c|c|c|c|c|c|c|c|c|c|}
\hline \multirow[b]{2}{*}{ Category } & \multirow[b]{2}{*}{$\begin{array}{l}\text { Affected or } \\
\text { unaffected eyes }\end{array}$} & \multicolumn{4}{|c|}{ Peak latency } & \multicolumn{4}{|c|}{ Peak amplitude } \\
\hline & & $\begin{array}{l}\text { Number* } \\
\text { of eyes }\end{array}$ & $\begin{array}{l}\text { Mean } \\
\text { latency (ms) }\end{array}$ & $S D$ & $\begin{array}{l}\text { Range } \\
\text { (ms) }\end{array}$ & $\begin{array}{l}\text { Number } \\
\text { of eyes }\end{array}$ & $\begin{array}{l}\text { Mean } \\
\text { amplitude }(\mu V)\end{array}$ & $S D$ & $\begin{array}{l}\text { Range } \\
(\mu V)\end{array}$ \\
\hline Control & Unaffected & 70 & $98 \cdot 5$ & $5 \cdot 6$ & $88-115$ & 70 & $15 \cdot 8$ & $5 \cdot 3$ & $8 \cdot 1-32 \cdot 0$ \\
\hline 1 & $\begin{array}{l}\text { Unaffected } \\
\text { Affected }\end{array}$ & $\begin{array}{l}16 \\
40\end{array}$ & $\begin{array}{l}104 \cdot 1 \\
126 \cdot 1\end{array}$ & $\begin{array}{r}7 \cdot 3 \\
13 \cdot 8\end{array}$ & $\begin{array}{r}93-115 \\
100-160\end{array}$ & $\begin{array}{l}16 \\
40\end{array}$ & $\begin{array}{l}16 \cdot 5 \\
16 \cdot 5\end{array}$ & $\begin{array}{l}5.4 \\
5.9\end{array}$ & $\begin{array}{l}7 \cdot 6-26 \cdot 1 \\
7 \cdot 6-30 \cdot 7\end{array}$ \\
\hline 2 & $\begin{array}{l}\text { Unaffected } \\
\text { Affected }\end{array}$ & $\begin{array}{l}11 \\
42\end{array}$ & $\begin{array}{r}99 \cdot 7 \\
134 \cdot 4\end{array}$ & $\begin{array}{r}5 \cdot 6 \\
12 \cdot 9\end{array}$ & $\begin{array}{r}90-110 \\
113-180\end{array}$ & $\begin{array}{l}11 \\
53\end{array}$ & $\begin{array}{r}13.0 \\
3.7\end{array}$ & $\begin{array}{l}5 \cdot 0 \\
2 \cdot 6\end{array}$ & $\begin{array}{r}8 \cdot 4-20 \cdot 8 \\
0-7 \cdot 4\end{array}$ \\
\hline 3 & Affected & 28 & $111 \cdot 1$ & $5 \cdot 6$ & $100-118$ & 33 & $3 \cdot 6$ & $2 \cdot 1$ & $0-7.0$ \\
\hline 4 & Affected & 6 & $110 \cdot 7$ & 5.0 & $105-118$ & 12 & $2 \cdot 3$ & $2 \cdot 4$ & $0-5 \cdot 0$ \\
\hline
\end{tabular}

- The reason why the numbers of eyes for the latency measurements for patients in category 3 and 4 are smaller than those for the amplitude measurements is that no measurement of latency could be made where the amplitude was zero.

Table 3 Interocular difference in the peak latency of the pattern VER

\begin{tabular}{llccl}
\hline Classification & $\begin{array}{l}\text { Number of } \\
\text { eyes } \\
\text { pair }\end{array}$ & $\begin{array}{l}\text { Mean } \\
\text { difference } \\
(m s)\end{array}$ & $S D$ & $\begin{array}{l}\text { Range } \\
(\mathrm{ms})\end{array}$ \\
\hline Control & 35 & 0.35 & 0.92 & $0-3$ \\
Category 1 & 28 & 12.54 & 9.23 & $0-40$ \\
Category 2 & 24 & 19.13 & 16.16 & $0-55$ \\
Category 3 & 13 & 1.00 & 1.58 & $0-5$ \\
Category 4 & 3 & 4.00 & 1.00 & $3-5$ \\
\hline
\end{tabular}

Comparison of ERG in patients under different categories

The ERGs were performed on $8,9,15$, and 6 patients in categories $1,2,3$, and 4, respectively. Figs.4A, $B, C$, and $D$ show the mean and standard error of the ERG b-wave amplitude as a function of relative $\log$ intensity of the stimulus flash (white) for patients in each of the 4 categories. In each graph the normal limit of the same function obtained from 200 normal subjects (age ranging between 8 and 65) collected over several years in the unit is shown as a shaded band (Ikeda, 1976).

Figs. $5 A, B, C$, and $D$ show the mean and standard deviation of the ERG b-wave wavelet amplitude as a function of flicker rate of stimulus of red transmission using a deep red narrow-cut filter (Kodak colour separation filter 29). This function mainly reveals cone mediated response.

Thus the normal ERG must satisfy the following 3 criteria: (1) The threshold log intensity (the weakest intensity which produces a measurable scotopic b-wave) is below $\overline{5} \cdot 0$. (2) The slope of the b-wave/ intensity is over $100 \mu \mathrm{V} / 1-\log$ unit intensity increment. (3) The red flicker ERG wavelets at $30 \mathrm{~Hz}$ are over $100 \mu \mathrm{V}$.
As Figs. $4 A$ and $5 A$ show, the patients who came into category 1 showed normal ERG functions. However, the patients who had been put in category 2 (the VERs were not only delayed but also signi-

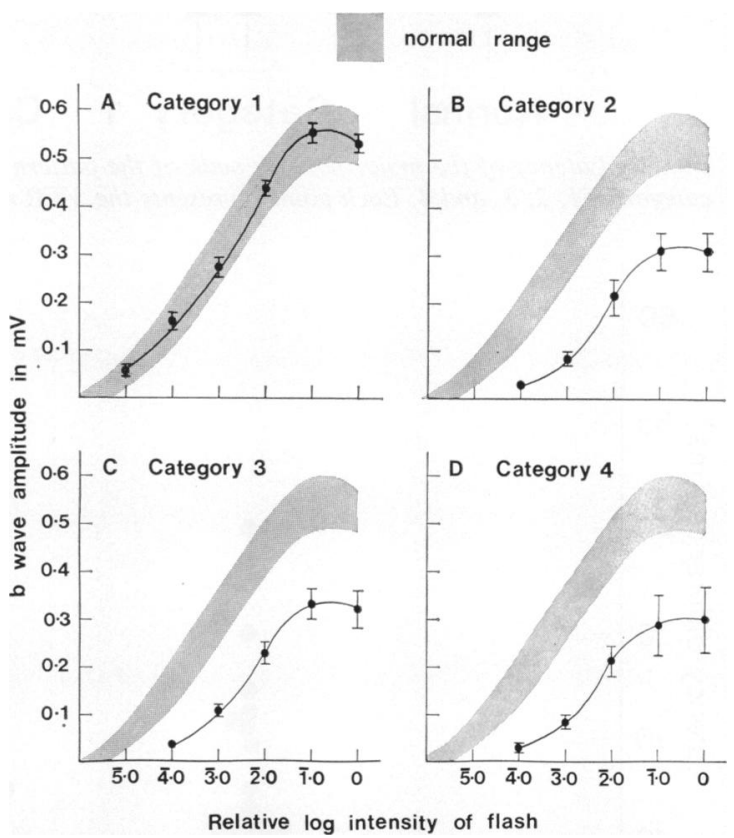

Fig. 4 Relation between ERG b-wave amplitude and relative log intensity of the flash that evoked it, in the 4 categories of patient. Each point is the mean $\pm S E$ of the $b$-wave amplitude at the given flash intensity of all patients in that category whose ERG was recorded. The shaded area indicates the normal range of $b$-wave amplitudes recorded from over 200 normal subjects in the authors' clinic. The b-wave intensity function in categories 2, 3, and 4 are all significantly reduced $(P<0.05)$. Where SEs are not indicated they lie within the size of the point 
cantly reduced) showed subnormal ERG functions (Figs. $4 B$ and $5 B$ ). It was noted, however, that in this group the ERG results varied rather widely from one patient to the other, ranging from relatively normal to extremely subnormal.

The reduction in the ERG functions were also apparent for patients in category 3 (Figs. $4 C$ and $5 C$ ) and for category 4 (Figs. $4 D$ and $5 D$ ), suggesting obvious retinal involvements in these cases.

Table 4 lists numbers of patients in each category and their age range, sex, and proportion of unilateral and bilateral conditions. Since all studies were done under monocular conditions for both VER and ERG, the number of eyes studied is also listed. Because a certain proportion of patients who came into categories 1 and 2 showed unilateral defects, for these groups the total numbers of affected and unaffected eyes are shown in Table 4.

Clinical correlates with the classification by the VER and the ERG

Having asserted the VER and ERG results, we looked for clinical correlation by reviewing the case notes of the 85 patients.

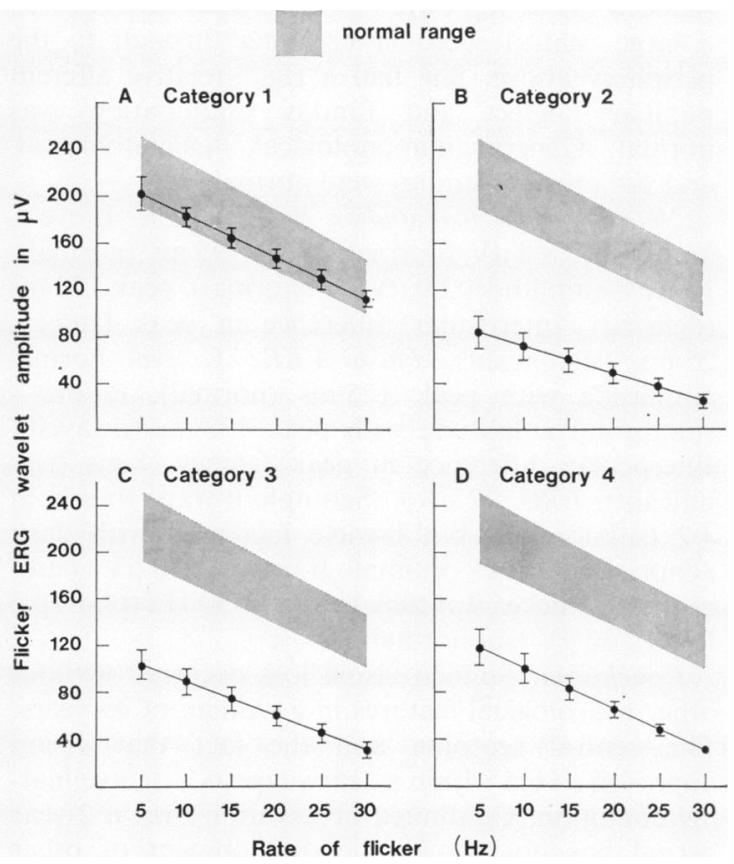

Fig. 5 Relation between ERG b-wavelet amplitude and rate of flicker of a red flash in the 4 categories of patient. Each point is the mean $\pm S E$, at the given rate of flicker, of all patients in that category whose ERG was recorded. The shaded area indicates the normal range. The photopic flicker function was significantly reduced $(P<0.01)$ in categories 2, 3, and 4. Where SEs are not indicated they lie within the size of the point
Table 4 Number of patients and eyes in each category

\begin{tabular}{|c|c|c|c|c|c|}
\hline Classification & $\begin{array}{l}\text { Age range } \\
\text { (mean) } \\
\text { (years) }\end{array}$ & $\begin{array}{l}\text { Number } \\
(\%)\end{array}$ & Sex & $\begin{array}{l}\text { Unilateral } \\
\text { or } \\
\text { bilateral }\end{array}$ & $\begin{array}{l}\text { Number of } \\
\text { eyes } \\
\text { studied }\end{array}$ \\
\hline Category 1 & $\begin{array}{l}18-56 \\
(43 \cdot 5)\end{array}$ & $\begin{array}{l}28 \\
(33 \cdot 7 \%)\end{array}$ & $\begin{array}{l}7 \mathrm{M} \\
1 \mathrm{~F}\end{array}$ & $\begin{array}{l}16 \mathrm{U} \\
12 \mathrm{~B}\end{array}$ & $\begin{array}{l}56 \\
40 \text { affected } \\
16 \text { unaffected }\end{array}$ \\
\hline Category 2 & $\begin{array}{l}24-70 \\
(44 \cdot 4)\end{array}$ & $\begin{array}{l}32 \\
(38.6 \%)\end{array}$ & $\begin{array}{l}17 \mathrm{M} \\
15 \mathrm{~F}\end{array}$ & $\begin{array}{l}11 \mathrm{U} \\
21 \mathrm{~B}\end{array}$ & $\begin{array}{l}64 \\
53 \text { affected } \\
11 \text { unaffected }\end{array}$ \\
\hline Category 3 & $\begin{array}{l}30-61 \\
(46 \cdot 2)\end{array}$ & $\begin{array}{l}17 \\
(20.5 \%)\end{array}$ & $\begin{array}{r}11 \mathrm{M} \\
6 \mathrm{~F}\end{array}$ & $16^{*} \mathrm{~B}$ & $\begin{array}{l}33 \\
33 \text { affected } \\
0 \text { unaffected }\end{array}$ \\
\hline Category 4 & $\begin{array}{c}34-61 \\
(50 \cdot 5)\end{array}$ & $\begin{array}{l}6 \\
(7 \cdot 2 \%)\end{array}$ & $\begin{array}{l}5 \mathrm{M} \\
1 \mathrm{~F}\end{array}$ & $\begin{array}{l}0 \mathrm{U} \\
6 \mathrm{~B}\end{array}$ & $\begin{array}{l}12 \\
12 \text { affected } \\
0 \text { unaffected }\end{array}$ \\
\hline $\begin{array}{l}\text { Combined } \\
\text { categories } \\
\text { total }\end{array}$ & & $\begin{array}{l}83 \\
(100 \%)\end{array}$ & $\begin{array}{l}41 \mathrm{M} \\
43 \mathrm{~F}\end{array}$ & $\begin{array}{l}28 \mathrm{U} \\
57 \mathrm{~B}\end{array}$ & $\begin{array}{l}165 \\
138 \text { affected } \\
27 \text { unaffected }\end{array}$ \\
\hline
\end{tabular}

* Glass eye.

Clinical picture common for the patients in category I (normal ERG, VER with normal amplitude but delayed $(P<0.001)$, or interocular difference in peak $(P<0.001))$

Of 28 patients $17(60.7 \%)$ were sent from neurology departments of different hospitals and $11(39.3 \%)$ from eye departments. The patients referred from the neurology departments usually had no history of visual symptoms. In these patients multiple lesions suggested a neurological diagnosis of multiple sclerosis. In some cases CSF IgG changes were present. The patients referred from the eye departments on the other hand often presented with a history of sudden loss of vision followed by spontaneous recovery and usually accompanied by pain in the affected eye. Examination showed reduced vision (acuity, colour vision), pupillary defects, and often disc leakage when examined by fluorescein angiography.

CASE A

A 24-year-old girl with a 12-month history of unusual sensory phenomena in the right upper arm and numbness in the right hand. Six months previously she noticed weakness of the legs, and 6 weeks prior to admission she lost vision in the right eye. Her visual acuity was reduced to $6 / 36$ but returned subsequently to normal.

On admission ocular examination showed vision of $6 / 5$ in each eye with a slightly reduced macular threshold in the right eye and a normal peripheral visual field. The right optic disc showed mild temporal pallor.

Neurological examination showed that the other cranial nerves were intact and motor and sensory testing was normal. She had brisk reflexes in all limbs and bilateral extensor plantars. CSF examina- 
tion showed a normal protein content and $14 \times 10^{9} / 1$ white cells which were mainly lymphocytes.

Neurophysiological studies. Pattern VER: L eyeamplitude, $17 \mu \mathrm{V}$ (normal), peak, $102 \mathrm{~ms}$ (normal). $\mathrm{R}$ eye-amplitude, $14 \mu \mathrm{V}$ (normal), peak, $125 \mathrm{~ms}$ (delayed). Interocular difference in peak time, $23 \mathrm{~ms}$ (significant). Flash VER: L eye-normal amplitude, peak, $110 \mathrm{~ms}$ (normal). $\mathrm{R}$ eye-normal amplitude, peak, $135 \mathrm{~ms}$ (delayed). Interocular difference in peak time, $25 \mathrm{~ms}$ (significant). ERG ( $R$ eye): scotopic b-wave threshold $\overline{5} \cdot 2$ (normal). The optimal b-wave amplitude, $500 \mu \mathrm{V}$ (normal). Normal increase in b-wave with dark adaptation. Flicker wavelets to red at $30 \mathrm{~Hz}$ (photopic ERG), $120 \mu \mathrm{V}$ (normal).

Diagnosis: Unilateral optic neuritis in association with multiple sclerosis.

Clinical picture common for the patients in category 2 (subnormal ERG $(P<0.01), V E R$ with subnormal amplitude $(\boldsymbol{P}<0.001)$ and delayed peak $(\boldsymbol{P}<0.001)$ Our survey of the patients in category 2 showed a wide range of clinical presentation. Visual loss was the main feature and this was often more severe and permanent. There were $6(18.8 \%)$ with suspected ischaemic optic neuropathies and $5(15.6 \%)$ with chiasmal or optic nerve compression. (No patients in category 1 , on the other hand, suffered from ischaemic or compressive lesions.) Furthermore, $66 \%$ of the patients showed a bilaterally delayed subnormal VER in contrast to $43 \%$ in category 1 . And the ERG functions were, to our surprise, subnormal in the affected eyes of these patients in category 2 . The following 2 cases $(B$ and $C$ ) would perhaps illustrate the clinical picture of the patients in this category.

CASE B

A 56-year-old man was referred with a 3-week history of blurred vision in the inferior part of the right field. The onset was sudden and he noticed it on waking in the morning. It has persisted unchanged since then. He had no previous illnesses and his general cardiovascular and respiratory systems were normal.

Ocular examination showed vision of 6/9 N5 right and $6 / 5 \mathrm{~N} 5$ left, and the visual fields showed a right inferior altitudinal field defect. Fundus examination showed pallid swelling of the right optic disc particularly below, and fluorescein angiography demonstrated attenuated arterioles, dilated disc capillaries at the lower disc margin, and diffuse asymmetric leakage of dye. Haematological investigations showed elevated serum triglycerides, but serological tests and investigations for hyperviscosity were normal.

Neurophysiological studies. Pattern VER: L eye- amplitude, $15.6 \mu \mathrm{V}$ (normal), peak $97 \mathrm{~ms}$ (normal). $\mathrm{R}$ eye-amplitude, $6 \cdot 2 \mu \mathrm{V}$ (subnormal), peak $117 \mathrm{~ms}$ (delayed). Interocular difference in the peak latency, $20 \mathrm{~ms}$ (significant). Flash VER: L eye-normal amplitude with peak $120 \mathrm{~ms}$ (normal). R eye-subnormal amplitude with peak $130 \mathrm{~ms}$ (slightly delayed). Interocular difference in peak latency, $10 \mathrm{~ms}$ (significant). ERG ( $R$ eye): Scotopic b-wave threshold $\overline{\mathbf{4}} \cdot 2$ (slightly subnormal) but b-wave increased with dark adaptation. The optimal b-wave, $410 \mu \mathrm{V}$ (slightly subnormal).

Conclusion: This patient has a right ischaemic papillopathy.

CASE C

A 49-year-old woman awoke one morning with visual loss in the right eye. There was no pain on ocular movement. Apart from pulmonary tuberculosis and a cholecystectomy there were no relevant previous illnesses and there were no familial illnesses. General examination showed a normal cardiovascular, respiratory, and neurological system.

Ocular examination showed vision of $6 / 36$ in the right eye and $6 / 6$ in the left eye. Colour vision was reduced in the right eye and the visual field showed a large central scotoma breaking through to the periphery above. She had a right relative afferent pupillary defect and fundus examination was normal. General immunological, haematological, and radiological studies were normal.

Neurophysiological studies. Pattern VER: L eyeamplitude, 8.4 $\mu \mathrm{V}$ (normal), peak, $95 \mathrm{~ms}$ (normal). $\mathrm{R}$ eye-amplitude, $2.0 \mu \mathrm{V}$ (subnormal), peak $120 \mathrm{~ms}$ (delayed). Interocular difference in peak latency, $25 \mathrm{~ms}$ (significant). Flash VER: L eye-normal amplitude with peak $125 \mathrm{~ms}$ (normal). $\mathrm{R}$ eyesubnormal amplitude with peak $133 \mathrm{~ms}$ (delayed). Interocular difference in peak latency, $8 \mathrm{~ms}$ (significant). ERG ( $R$ eye): Scotopic b-wave threshold $\overline{4} \cdot 2$ (subnormal), but b-wave increased with dark adaptation. The optimal b-wave, $380 \mu \mathrm{V}$ (subnormal). Flicker wavelets to red at $30 \mathrm{~Hz}$ (photopic ERG), $30 \mu \mathrm{V}$ (subnormal).

Conclusion: Sudden visual loss occurred without other neurological features in a woman of 49 years. The central scotoma and the fact that vision improved to $6 / 5$ within a year suggests a demyelinating condition. Continued observation over a 2-year period has not shown the development of other neurological signs.

Clinical picture common for the patients in category 3 (subnormal ERG-P<0.005, subnormal VER$P<0.001$, with no delay and no interocular difference in the peak)

Unlike the first 2 categories all the patients in this 
category had bilateral visual disturbance. A central scotoma was common and in some cases the VER was already abolished. All patients in category 3 with progressive painless deterioration of vision had a provisional diagnosis of toxic amblyopia. It should be noted that 1 case in this category was of West Indian amblyopia and the other of quinine amblyopia. The remaining 15 patients $(88.2 \%)$ had a long history of smoking or drinking. In 4 cases of alcohol and tobacco amblyopia the VER and ERG were recorded before and after a course of vitamin $B_{12}$ treatment together with the withdrawal of these toxic substances (Table 5). After the combination of abstinence and the treatment, the VER and ERG improved in 3 out of the 4 patients. Thus for the patients in this category the impairment of visual function should be reversible. Patient 4 , who never admitted her drinking habits (although her excessive alcohol intake was confirmed by relatives and neighbours) failed to discontinue alcohol and failed to respond to the treatment. The VER and ERG showed a further deterioration instead of improvement.

A representative case $(D)$ in category 3 is shown below. This case is included as case 2 in Table 5.

\section{CASE D}

A 48-year-old man was admitted with bilateral visual loss over the past 2 years. Progressive deterioration had occurred over this period.

Personal history. He was a company director whose day began with a gin before breakfast, several gins at lunchtime, and a number of whiskies before retiring at night. His diet included a sandwich during the day and possibily an egg at night. He smoked up to 8 cigars daily for several years. General examination showed a slightly obese man with some signs of premature ageing. Cardiovascular examination showed mild hypertension and a liver palpable 4 fingers below the right costal margin. There was some evidence of mental deterioration with inability to perform serial $7 \mathrm{~s}$ and the Babcock sentence. Neurological examination was otherwise normal.

Vision was counting fingers in the right eye and N48 for near and in the left eye 6/18 and N12. Colour vision showed a moderate colour defect in both eyes (AO-HRR testing). Visual field testing showed a central scotoma in both eyes but more marked on the right than on the left. Fundus examination showed mild temporal pallor of the optic discs.

Investigations included a plasma gamma GT of $509 \mathrm{mU} / \mathrm{ml}$, alkaline phosphatase 14.0 units $/ 100 \mathrm{ml}$, $\mathrm{RBC}$ folate $130 \mathrm{mg} / \mathrm{ml}$ (slightly reduced), VDRL and TPHA negative, plasma proteins $17 \cdot 5 \mathrm{~g} / 1$, and plasma bilirubin $1.8 \mathrm{mg} / 100 \mathrm{ml}(31 \mu \mathrm{mol} / \mathrm{l})$. Neurophysiological studies (see Table 5, Case 2). In addition flash VERs were also subnormal in amplitude without any delay in peak times (120 to $125 \mathrm{~ms}$ ) for both eyes, and the electro-oculogram (EOG) sensitivity to light was also subnormal.

Conclusion: A patient with a history of visual loss, heavy alcohol and tobacco intake, and inadequate diet diagnosed as toxic optic neuropathy.

Table 5 Effect of $B_{12}$ treatment assessed by VER and ERG in toxic amblyopia cases

\begin{tabular}{|c|c|c|c|c|c|c|c|c|c|}
\hline Patient & $\operatorname{Sex}$ & Age & Toxic substance & Treatment & $V E R$ and ERG measures & $\begin{array}{l}\text { Before } t r \\
R\end{array}$ & $\stackrel{\text { atment }}{L}$ & $\begin{array}{l}\text { After tred } \\
R\end{array}$ & $\stackrel{t m e n t}{L}$ \\
\hline 1 & $\mathbf{F}$ & 54 & $\begin{array}{l}\text { Tobacco and } \\
\text { alcohol }\end{array}$ & $\mathrm{B}_{12}$ injections & $\begin{array}{l}\text { VER amplitude } \\
\text { VER latency } \\
\text { ERG threshold } \\
\text { Flicker ERG }(30 \mathrm{~Hz}) \\
\text { VA }\end{array}$ & $\begin{array}{l}4.4 \mu \mathrm{V} \\
115 \mathrm{~ms} \\
- \\
-\end{array}$ & $\begin{array}{l}3.4 \mu \mathrm{V} \\
115 \mathrm{~ms} \\
\overline{4} \cdot 0 \\
20 \mu \mathrm{V} \\
6 / 24\end{array}$ & $\begin{array}{l}8.7 \mu \mathrm{V} \\
108 \mathrm{~ms} \\
- \\
-\end{array}$ & $\begin{array}{l}6.0 \mu \mathrm{V} \\
110 \mathrm{~ms} \\
\frac{1}{5} \cdot 0 \\
75 \mu \mathrm{V} \\
6 / 5\end{array}$ \\
\hline 2 & $\mathbf{M}$ & 48 & Alcohol & $\begin{array}{l}\mathrm{B}_{12} \text { injections } \\
\text { Heminevrine } \\
\text { tablets }\end{array}$ & $\begin{array}{l}\text { VER amplitude } \\
\text { VER latency } \\
\text { ERG threshold } \\
\text { Flicker ERG }(30 \mathrm{~Hz} \\
\text { VA }\end{array}$ & $\begin{array}{l}2 \cdot 9 \mu \mathrm{V} \\
105 \mathrm{~ms} \\
\overline{4} \cdot 0 \\
5 \mu \mathrm{V} \\
\mathrm{CF}\end{array}$ & $\begin{array}{l}6.5 \mu \mathrm{V} \\
100 \mathrm{~ms} \\
- \\
- \\
6 / 18\end{array}$ & $\begin{array}{l}8.4 \mu \mathrm{V} \\
100 \mathrm{~ms} \\
\overline{5} \cdot 0 \\
25 \mu \mathrm{V} \\
6 / 36\end{array}$ & $\begin{array}{l}10 \cdot 3 \mu \mathrm{V} \\
100 \mathrm{~ms} \\
- \\
-\end{array}$ \\
\hline 3 & $\mathbf{M}$ & 36 & $\begin{array}{l}\text { Tobacco and } \\
\text { alcohol }\end{array}$ & $\mathbf{B}_{12}$ injections & $\begin{array}{l}\text { VER amplitude } \\
\text { VER latency } \\
\text { ERG threshold } \\
\text { Flicker ERG }(30 \mathrm{~Hz}) \\
\text { VA }\end{array}$ & $\begin{array}{l}2 \cdot 5 \mu \mathrm{V} \\
118 \mathrm{~ms} \\
\overline{3} \cdot 5 \\
4 \mu \mathrm{V} \\
6 / 24\end{array}$ & $\begin{array}{l}3.4 \mu \mathrm{V} \\
118 \mathrm{~ms} \\
- \\
6 / 6\end{array}$ & $\begin{array}{l}10 \cdot 3 \mu \mathrm{V} \\
100 \mathrm{~ms} \\
\frac{4}{4} \cdot 5 \\
30 \mu \mathrm{V} \\
6 / 5\end{array}$ & $\begin{array}{l}8.4 \mu \mathrm{V} \\
100 \mathrm{~ms} \\
- \\
\overline{6 / 6}\end{array}$ \\
\hline 4 & $\mathbf{F}$ & 61 & Alcohol & $\begin{array}{l}\mathbf{B}_{12} \text { injections } \\
\text { Orovite tablets } \\
\quad \text { (not stopped } \\
\text { drinking) }\end{array}$ & $\begin{array}{l}\text { VER amplitude } \\
\text { VER latency } \\
\text { ERG threshold } \\
\text { Flicker ERG }(30 \mathrm{~Hz} \text { ) } \\
\text { VA }\end{array}$ & $\begin{array}{l}3 \cdot 1 \mu \mathrm{V} \\
118 \mathrm{~ms} \\
\overline{4} \cdot 5 \\
50 \mu \mathrm{V} \\
6 / 24\end{array}$ & $\begin{array}{l}5.6 \mu \mathrm{V} \\
115 \mathrm{~ms} \\
- \\
- \\
6 / 12\end{array}$ & $\begin{array}{l}2.8 \mu \mathrm{V} \\
123 \mathrm{~ms} \\
\overline{4} \cdot 5 \\
25 \mu \mathrm{V} \\
6 / 24\end{array}$ & $\begin{array}{l}3 \cdot 2 \mu \mathrm{V} \\
125 \mathrm{~ms} \\
- \\
- \\
6 / 12\end{array}$ \\
\hline
\end{tabular}


Clinical picture common for the patients in category 4 (the ERG and VER results are the same as those for category 3, i.e., bilaterally subnormal ERG and $V E R$ with no delay)

The patients in this category could not be distinguished from those of category 3 on the basis of the VER and ERG, but all came to the unit with a long history of progressive painless visual loss and bilateral optic atrophy of no known cause. They were distinguished from those of category 3 patients because they did not smoke or drink and there was no evidence of West Indian amblyopia. A family history of visual loss was persistently absent. The following illustrated case shows a typical clinical picture of the patients in this category.

CASE E

A 57-year-old man was admitted with recent reduction in visual acuity. He had been attending an optician for 30 years.

Past history and investigations. He had malaria in West Africa. Otherwise no previous illnesses. Cardiovascular, respiratory, and neurological systems were all normal. Ophthalmic examination showed visual acuity of $6 / 12$ N5 right, and 6/24 N8 left. Colour vision testing showed a marked red/ green defect in both eyes (AO-HRR testing). Ocular movements were normal. Fundus examination was normal apart from bilateral optic atrophy.

Routine haematological and immunological studies were normal. VDRL and TPHA were negative in both blood and CSF. CSF protein $0.1 \mathrm{mg} / 1$, immunoglobulin levels in CSF IgG trace, IgM nil. Leucocytes less than $1 \mathrm{cell} / \mathrm{mm}^{3}$. Skull and optic canal $x$-rays normal.

Neurophysiological studies. Pattern VER: R eyeamplitude, $4.5 \mu \mathrm{V}$ (subnormal), peak, very broad, $112 \mathrm{~ms}$ (normal). L eye-amplitude, $3.7 \mu \mathrm{V}$ (subnormal), peak, very broad, $114 \mathrm{~ms}$ (normal). Interocular difference in the peak, $2 \mathrm{~ms}$ (insignificant). Flash VER: Subnormal amplitude with broad peak, $125 \mathrm{~ms}$ (normal) for both eyes. $E R G$ ( $L$ eye) : Scotopic b-wave threshold, $\overline{4} \cdot 2$ (subnormal). The optimal b-wave amplitude, $350 \mu \mathrm{V}$ (subnormal), flicker wavelets to red at $30 \mathrm{~Hz}, 20 \mu \mathrm{V}$ (subnormal). In addition electro-oculogram (EOG) sensitivity to light was subnormal in both eyes.

Conclusion: A patient with bilateral optic atrophy of unknown cause, and a continued examination over 2 years has shown no alteration.

\section{Discussion}

We have shown that patients with optic nerve lesions can be divided into 4 categories on the basis of the
VER and ERG results correlated with clinical observations.

Despite the diversity in the clinical observations, in the patients in category 1 the VERs showed a normal amplitude but a delayed peak. The ERGs were normal. These observations suggested that the electrical activity of the retina was normal, but the conduction to the brain had been slowed. The results strongly suggest a lesion in the myelin sheath of the optic nerve fibres, i.e., demyelination, and there are many studies on the VER delay in demyelinating diseases (Halliday et al., 1972, 1973a, 1973b; Arden, 1973; Asselman et al., 1975; Regan et al., 1976; Halliday and McDonald, 1977; McDonald and Halliday, 1977; Hennerici et al., 1977).

McDonald and Sears (1970) described how demyelination due to diphtheria toxin leads to slowing of conduction. McDonald (1976) classified the effects of demyelination of optic nerve fibres on conductivity into (1) slowing of conduction if the lesion is small, and (2) complete conduction block if the lesion is large. The patients in category 1 appear to come in the first group in McDonald's classification. In this respect we should pay particular attention to the patients with a significant interocular difference in the peak latency, i.e., beyond $5 \mathrm{~ms}$. Our normal for the interocular difference in the peak latency is much smaller ( $3 \mathrm{~ms}$, i.e., the mean difference $+\mathrm{x} \times$ SD) than that $(7 \mathrm{~ms})$ reported by Asselman et al. (1975). Interocular latency difference in the patients in category 1 varied between 5 and $10 \mathrm{~ms}$, though the difference was as great as 20 to $40 \mathrm{~ms}$ in some cases. As McDonald (1976) states, 5 to 10 -ms delay could be expected if demyelination of optic nerve fibres occurred over $1 \mathrm{~cm}$ (which is one-fifth of the optic nerve length). As shown below, our calculation agrees with this.

For the bilateral cases in which the peak latency of the VERs from both eyes was delayed we cannot say whether the delay is significant until the peak latency is longer by $16 \mathrm{~ms}$ from the mean normal peak latency in the control subjects. This corresponds to three times the standard deviation, and our calculation suggests that $16-\mathrm{ms}$ delay would be expected if the demyelination had occurred over 1.5 to $2 \mathrm{~cm}$ of the optic nerve or tract fibres. Thus, this makes the detection of demyelination by the VERs in such patients with bilateral involvement insensitive compared with that using the interocular latency difference. However, 10 out of 12 patients who showed bilateral delay of over $16 \mathrm{~ms}$ also showed an interocular latency difference beyond $5 \mathrm{~ms}$.

The findings of a 20-ms delay in the peak latency of the major positive wave of the VER is not unique in well-established cases of multiple sclerosis, in which a delay as large as $100 \mathrm{~ms}$ has been found 
(Halliday et al., 1973b; Asselman et al., 1975). Such a considerable delay in conduction without blocking or reducing the overall excitability is difficult to explain except in terms of slow continuous conduction across demyelinated segments of small myelinated fibres (Bostock and Sears, 1976). If we suppose demyelination occurred over $1,2,3,4$, and $5 \mathrm{~cm}$ of the optic nerve or tract, or radiation fibres and the conduction at the demyelinating segments slowed to $1 \mathrm{~m} / \mathrm{s}$ from the original $10 \mathrm{~ms}$ (assuming the macular bundle fibres of the human to be similar to those of very fine myelinated 'sustained' or ' $\mathrm{X}$ ' fibres in the cat (Ikeda and Wright, 1972), the expected delay is $9,18,27,36$, and $45 \mathrm{~ms}$, respectively. Indeed the delays in the peak latency of the positive wave of the VER in the category 1 patients are within this range.

Clinical observations on the patients in category 2 did not differ substantially from those in category 1. However, subnormal amplitude and delayed VER with subnormal ERG functions were the characteristics of the patients in category 2 . Interocular latency difference was also significant. These findings suggest lesions in axons and the retina, as well as in myelin.

Clinically the category 2 patients could be divided into 2 subgroups: (1) patients with demyelinating disease with large lesions, thus with some conduction block or breakdown of slow saltatory conduction along demyelinating fibres (McDonald, 1976); and (2) patients with optic neuropathies caused by ischaemia or damage caused by compression or trauma.

It has previously been shown that the VER is delayed in cases of ischaemic optic neuropathy (Hennerici et al., 1977) and optic nerve compression (Halliday, 1976; Halliday et al., 1976). However, the reduction in the amplitude of the VER has never been seriously considered by previous workers owing to a wide variability in this measure. Despite the variability we are, nevertheless, able to use the amplitude reduction as an important indicator for axonal and retinal involvement. Indeed, one would expect a basic difference between patients with primary demyelination and those with ischaemic or compressive lesions. Ischaemia giving rise to anoxia would affect not only the optic nerve (both axons as well as myelin), but also all the enzymic and transport processes within the cell body, dendrites and axon and axon terminals (see Siegel et al., 1976). Here not only orthograde but also retrograde degeneration can be expected.

Indeed it is well known that section of the optic nerve causes orthograde transneuronal degeneration in the lateral geniculate nucleus (Mathews et al., 1960; Kupfer and Palmer, 1964; Garey et al., 1973).
If the axons themselves were involved in the disease process, therefore, orthograde degeneration in the higher order neurones would be expected and the excitation of visual cortical cells could not be normal. A subnormal VER would therefore be a consequence.

Can retrograde transneuronal degeneration extending to the bipolar cells (the generator of the b-wave of the ERG) occur after an optic nerve lesion? The patients in category 2 who appeared to suffer from either an extensive demyelinating disease or ischaemic or compressive lesions of the optic nerve or tract fibres showed a significant loss of ERG functions, suggesting a reduced excitation of the bipolar cells in the retina. An extreme retrograde transneuronal loss of central retinal ganglion cells was shown to occur after ablation of cortical area 17 in the monkey, involving at least 2 synapses (Cowey, 1974). It would not, therefore, be surprising that the optic nerve lesion could at least affect the retinal bipolar cell function, if not causing 'degeneration'. Indeed retrograde transneuronal degeneration is most likely to occur in parts of the central nervous system when there is little divergence of efferent connection (Watson, 1976), and this is true for the human optic nerve.

The patients with toxic amblyopia (category 3) showing some form of optic neuropathy give an entirely different picture from those of the first two categories. As the cause suggests, they had exclusively bilateral and painless progressive visual loss. By the time the condition had been arrested by treatment, the VERs were extremely reduced in amplitude. Interestingly, however, delay in the peak latency was not a prominent feature. The ERG functions, particularly the cone mediated retinal function in all these cases, were significantly.reduced. The results suggest that nutritional deficiency or toxicity could have a major effect upon the enzymic and transport processes of the relay cells and axons rather than affecting the myelin sheath of the optic nerve fibre. Furthermore, the effect of the toxic substance will be generalised and not specific to the optic nerve. It should be noted that, so long as the toxic substance was withdrawn and vitamin $\mathbf{B}_{12}$ treatment given, the condition was reversible if its development was arrested at an early stage (Table 5 and the illustrated case).

The patients in category 4, showing bilateral optic atrophy of unknown cause, are perhaps the most intriguing group clinically. They show an extremely reduced VER with only marginal delay, and the ERG functions were subnormal as in category 3 patients. But the category 4 patients showed irreversible progressive degeneration. Since they do not show extreme delay in the VER, they 
cannot be in the advanced stage of category 1 and 2 groups. It is also highly improbable that these patients in category 4 are the advanced cases of the group in category 3 , since there is no evidence of an intake of toxic substance although the lesions appear to be at the same place. We had to exclude $68 \%$ of the original patients with bilateral optic atrophy because they showed some systemic involvement and/or some additional pathological changes in the fundi indicating an obvious retinal lesion or a suspected hereditary cause. Whether or not these patients in category 4 were suffering from optic atrophy due to undiagnosed systemic disorders or from a form of hereditary optic atrophy without any traceable family history was not certain. It should perhaps be mentioned that patients in this category showed a subnormal light rise in the electro-oculogram, suggesting that the outermost layer which initiates the visual excitation of the retina-i.e., the choroid, pigment epithelium, and the outer tips of the photoreceptors-was also affected. Further extensive and systematic analysis is required for the patients with bilateral optic atrophy in category 4 .

The present work has failed to confirm the supernormal ERGs previously reported in cases of optic nerve lesions (Jacobson and Suzuki, 1962; Gills, 1966; Feinsod et al., 1971). Such results have been used to support the hypothesis that there are centrifugal fibres in the optic nerve in the human eye and that the role of these is inhibitory in nature. The discrepancy could be due to differences in the sampling of cases, although there is evidence for a more sceptical attitude towards the question of centrifugal fibres to the mammalian retina and their functional role (see Brindley, 1970). In any case it would be surprising if our technique of recording the ERG even under the most rigorous controls could reflect a centrifugal influence which might be carried by efferent fibres totalling $1 \%$ of the optic nerve fibres (Cowan and Powell, 1963).

\section{Clinical implications}

The present study emphasises the value of neurophysiological investigation in patients with unilateral and bilateral visual loss. Accurate evaluation of subtle optic nerve dysfunction in patients with neurological disease has been greatly facilitated by the use of the VER.

The presence of a reduced ERG in patients with a subnormal amplitude VER raises important questions about functional depression of retinal function and transynaptic degeneration. From the clinical point of view these findings suggest that a normal ERG in a patient with optic nerve disease indicates sparing of axons, and demyelinating disease is the likely mechanism. A reduced ERG in contrast does not necessarily indicate primary retinal disease but may reflect retinal changes secondary to optic nerve disease. The finding in cases of toxic amblyopia of reduced ERGs and VERs may suggest diffuse optic nerve and retinal involvement, and the reversibility after therapy emphasises the need to recognise this condition. It may be difficult in some cases to distinguish neuroretinal from optic nerve disease (Sanders, 1976), and it is hoped that this paper will stimulate further experimental and clinical work in this sphere.

We are greatly indebted to the Prevention of Blindness Fund for giving us the ERG and VER equipment and to St. Thomas's Hospital for the financial aid for this work. We are also grateful to Professor T. Sears and Professor J. H. Wolstencroft for valuable comments on the manuscript. The authors are indebted to Professor I. McDonald and Dr M. Halliday for useful discussions on the topic. We thank Miss J. Lace, Mr B. Hodelin, and Mrs J. Turner for administrative and technical assistance.

\section{References}

Arden, G. B. (1973). The visual evoked responses in ophthalmology. Proceedings of the Royal Society of Medicine, 66, 1037-1043.

Asselman, P., Chadwick, D. W., and Marsden, C. D. (1975). Visual evoked responses in the diagnosis and management of patients suspected of multiple sclerosis. Brain, 98, 261-282.

Bostock, H., and Sears, T. A. (1976). Continuous conduction in demyelinated mammalian nerve fibres. Nature, 263, 786-787.

Brindley, G. S. (1970). Physiology of the Retina and Visual Pathway, 2nd edn., pp. 105-110. Edward Arnold: London.

Cowan, W. M., and Powell, T. P. S. (1963). Centrifugal fibres in the avian visual system. Proceedings of the Royal Society, B, 158, 232-252.

Cowey, A. (1974). Atrophy of retinal ganglion cells after removal of striate cortex in a rhesus monkey. Perception, 257-260.

Dawson, G. D. (1954). A summation technique for the detection of small evoked potentials. Electroencephalography and Clinical Neurophysiology, 6, 65-84.

Feinsod, M., Rowe, H., and Auerbach, E. (1971). Changes in the electroretinogram in patients with optic nerve lesions. Documenta Ophthalmologica, 29, 169-200.

Garey, L. J., Fiskin, R. A., and Powell, T. P. S. (1973). Effects of experimental deafferentation on cells in the lateral geniculate nucleus of the cat. Brain Research, 52, 363-369.

Gills, J. P. (1966). The electroretinogram after section of the optic nerve in man. American Journal of Ophthalmology, 62, 287-291.

Halliday, A. M. (1975). The effect of lesions of the visual pathway and cerebrum on the visual evoked response. In Evoked Potentials: Handbook of Electroencephalography and Clinical Neurophysiology, Vol. 8A, pp. 119-129. Edited by W. S. van Leeuwen, F. H. Lopes da Silva, and A. Kamp. Elsevier: Amsterdam. 
Halliday, A. M. (1976). Visually evoked responses in optic nerve disease. Transactions of the Ophthalmological Societies of the United Kingdom, 96, 372-376.

Halliday, A. M., Halliday, E., Kriss, A., McDonald, W. I., and Mushin, J. (1976). The pattern evoked potentials in compression of the anterior visual pathways. Brain, 99, 357-374.

Halliday, A. M., McDonald, W. I., and Mushin, J. (1972). Delayed visual evoked response in optic neuritis. Lancet, 1, 982-985.

Halliday, A. M., McDonald, W. I., and Mushin, J. (1973a). Delayed pattern-evoked responses in optic neuritis in relation to visual acuity. Transactions of the Ophthalmological Societies of the United Kingdom, 93, 315-324.

Halliday, A. M., McDonald, W. I., and Mushin, J. (1973b). Visual evoked response in diagnosis of multiple sclerosis. British Medical Journal, 4, 661-664.

Halliday, A. M., and McDonald, W. I. (1977). Pathophysiology of demyelinating discase. British Medical Bulletin, 33, $21-27$.

Hennerici, M., Wenzel, D., and Freund, H. J. (1977). The comparison of small-size rectangle and checkerboard stimulation for the evaluation of delayed visual evoked responses in patients suspected of multiple sclerosis. Brain, 100, 119-136.

Ikeda, H. (1976). Electrophysiology of the retina and visual pathway. In Medical Ophthalmology, pp. 38-55. Edited by F. Clifford Rose. Chapman \& Hall: London.

Ikeda, H., and Wright, M. J. (1972). Receptive field organisation of 'sustained' and 'transient' retinal ganglion cells which subserve different functional roles. Journal of Physiology, 227, 769-800.

Jacobson, J. H., and Suzuki, T. A. (1962). Effects of optic nerve section on the ERG. Archives of Ophthalmology, 67, 791-801.
Karpe, G. (1945). The basis of electroretinography. Acta Ophthalmologica, Suppl., 24,

Kupfer, C., and Palmer, P. (1964). Lateral geniculate nucleus: histological and cytochemical changes following afferent denervation and visual deprivation. Experimental Neurology, 9, 400-409.

Matthews, M. R., Cowan, W. M., and Powell, T. P. S. (1960). Transneuronal cell degeneration in the lateral geniculate nucleus of the macaque monkey. Journal of Anatomy, 94, 145-169.

McDonald, W. I. (1976). Conduction in the optic nerve. Transactions of the Ophthalmological Societies of the United Kingdom, 96, 352-354.

McDonald, W. I., and Halliday, A. M. (1977). Diagnosis and classification of multiple sclerosis. British Medical Bulletin, 33, 4-9.

McDonald, W. I., and Sears, T. A. (1970). The effects of experimental demyelination on conduction in the central nervous system. Brain, 93, 583-598.

Regan, D. (1972). Evoked Potentials in Psychology, Sensory Physiology and Clinical Medicine, pp. 76-79. Chapman \& Hall: London.

Regan, D., Milner, B. A., and Heron, J. R. (1976). Delayed visual perception and delayed visual evoked potentials in the spinal form of multiple sclerosis and in retrobulbar neuritis. Brain, 99, 43-66.

Sanders, M. D. (1976). Diagnostic difficulties in optic nerve disease and in papilloedema and disc oedema. Transactions of the Ophthalmological Societies of the United Kingdom, 96, 386.

Siegel, G. J., Albers, R. W., Katzman, R., and Agranoff, B. W., eds. (1976). Basic Neurochemistry. Little \& Brown: Boston.

Watson, W. E. (1976). Cell Biology of Brain, p. 259. Chapman \& Hall: London; John Wiley: New York. 